\title{
A QUANTITATIVE STUDY OF REACTIONS TO LIGHT IN AMOEBA ${ }^{1}$
}

\author{
H. T. FOLGER \\ Cniversity of Michigan
}

THREE FIGURES

\section{CONTENTS}

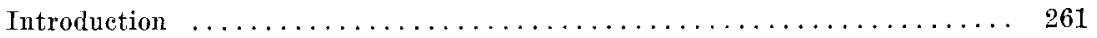

Materials and methods $\ldots \ldots \ldots \ldots \ldots \ldots \ldots \ldots \ldots \ldots \ldots \ldots \ldots \ldots \ldots \ldots$

The reaction-time, the stimulation-period, and the latent period....... 268

The stimulation-threshold and the intensity-threshold $\ldots \ldots \ldots \ldots \ldots \ldots \ldots 277$

Dark adaptation ............................. 279

Influence of the environment on the reaction-time $\ldots \ldots \ldots \ldots \ldots \ldots \ldots 28$

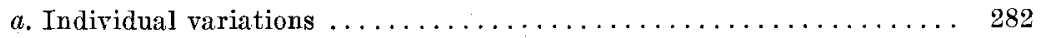

b. Relation between mechanical shock and the reaction to light...... 283

c. Influence of feeding on the reaction-time $\ldots \ldots \ldots \ldots \ldots \ldots \ldots \ldots \ldots$

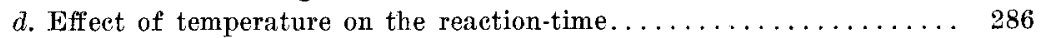

Discussion $\ldots \ldots \ldots \ldots \ldots \ldots \ldots \ldots \ldots \ldots \ldots \ldots \ldots \ldots \ldots \ldots \ldots \ldots \ldots \ldots$

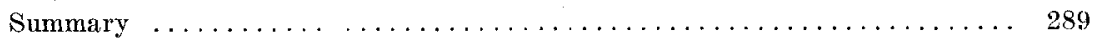

Literature cited $\ldots \ldots \ldots \ldots \ldots \ldots \ldots \ldots \ldots \ldots \ldots \ldots \ldots \ldots \ldots \ldots \ldots$

\section{INTRODUCTION}

The effect of light on organisms has long attracted attention. As early as 1693 Ray noted that a plant placed in a room grew toward the window. This he attributed to a difference in temperature on the two sides of the plant, though later investigations have easily proved the reaction to be due to light. Various workers have attacked the manifold problems connected with the response to illumination, such as aggregation, relative effects of light of different intensities or different wave lengths, orientation. Various theories have been advanced to account for these phenomena and

${ }^{1}$ Contribution from the Zoölogical Laboratory of The Johns Hopkins University. This work was undertaken at the suggestion of Prof. S. O. Mast and carried out under his direction. I wish to thank him for advice and criticism.

261

THE JOURNAL OF EXPERIMENTAL Zë̈lOGY, VOL. 41, No. 3 
many data collected from experiments. The work has, however, been largely qualitative. It is only recently that the problem has been attacked from a quantitative point of view.

The first results of a strictly quantitative nature were obtained from the study of the response to unilateral illumination in Avena seedlings. It has long been known that if a plant is kept in the dark and then exposed to light from one side the response will not occur immediately, and that illumination is not necessary for the whole of the time until the response does occur. That is, to give a concrete illustration, an exposure of five minutes may be sufficient to cause a plant to react, although the actual bending does not occur until some time later, let us say twenty minutes, after the light was first turned on. The time from the turning on of the light until the reaction takes place has been designated the reaction-time. Obviously, from what has been said, the reaction-time may be divided into two periods, a time during which the plant must be exposed to light in order to obtain a reaction, known as the presentation-time, or, as we shall call it, the stimulation-period, and a time during which it may or may not be exposed without altering the reaction, known as the latent period. Several investigators have studied the relation between the stimulating agent and these phases of the reaction. Blaauw ('09) and Fröschel ('09) maintain that the amount of light-energy required to induce bending toward the source of illumination in Avena seedlings has the same value in all intensities; that is, the product of the intensity of the light and the time during which it must act to produce a response is constant. Arisz ('11, '15) contends that this holds true for the point at which bending becomes macroscopically visible only, and that equal amounts of light do not necessarily produce equal effects.

Apparently of somewhat the same nature are those reactions found among both animals and plants which are dependent on sudden changes in intensity, and which are usually referred to as shock reactions (Mast, '11, pp. 246251). The reaction of the plasmodia of Mycetozoa, consist- 
ing of a cessation of movement when exposed to light, as described by Baranetski ('76) and Stahl ('84), probably belongs here. Ewart ('03) states that an increase in illumination may cause a retardation in protoplasmic streaming in the cells of various plants, and that to be effective the increase must be suddenly applied. This is a typical example of a shock reaction, in which there is a definite threshold. No effect is to be observed until after the energy received by the receptors has been increased by a certain amount, and the increase must take place within a comparatively short time.

In many other organisms besides the plants described above it is not necessary to expose the receptors continuously in order to induce a reaction. Mast ('12) observed that when fireflies are exposed to a flash of light, the response does not begin until after the light has disappeared. These insects fail to respond if the light is not cut off, but in various other animals the light may continue to act until after the reaction has taken place, even though a response might be obtained with a much shorter exposure.

Ewald ('14) states that the amount of light-energy required to bring about a response by suddenly illuminating the eye of Daphnia is the same over a large range of intensities. Hecht ('18, '19) reaches the same conclusion in reference to Ciona and Mya, as does also Obreshkove ('21) in reference to Rana tadpoles. These authors maintain that the latent period is constant for all intensities, and that the stimulationperiod is consequently inversely proportional to the intensitv.

Harder ('20) observed that Nostoc hormogonia respond to a sudden decrease in illumination by a cessation of the creeping movement characteristic of them, followed shortly afterward by the resumption of motion in the opposite direction. He studied the latter phase especially and contends that the time from the shutting off of the light until the reversal in direction is not proportional to the decrease in light intensity. 
Amoeba has been the subject of a number of investigations on the effects of light. Engelmann ('79) was the first to note the effect of a sudden increase in illumination on an amoeboid organism. He maintains that the pseudopod of Pelomyxa contracts when suddenly exposed to a beam of light and that locomotion ceases. Davenport ('97) asserts that A. proteus is negative to light, moving away from the source of illumination. Both Davenport and Verworn failed to obtain a response when an amoeba was allowed to move from a dark into an illuminated field. Harrington and Leaming ('00) hold that $A$. proteus responds to a sudden increase in intensity by a temporary cessation of movement. They also state that the shorter wave lengths are more effective in inducing stimulation than the longer. Mast ('10) found that orientation in Amoeba results from the cessation of pseudopod formation on the more highly illuminated side. $\mathrm{He}$ observed that when an amoeba reaches the edge of a beam of light it stops and reverses the direction of movement, and he is of the opinion that the time required decreases with experience. He found that a gradual increase of intensity produces no observable effect, and contends, consequently, that the response is dependent on the time rate of change. He also states that after streaming has ceased it usually begins again in a short time, even though the light is not turned off.

The present paper, which is based upon the reaction to light in Amoeba, is primarily concerned with the relation between the stimulating agent and those phases of the consequent response known as the reaction-time, the stimulationperiod, and the latent period.

\section{MATERIALS AND METHODS}

The experiments were carried out in a basement dark room, observations being made with a compound microseope. Light was obtained either from a 1000-watt, 112-volt, or 123-volt Westinghouse stereopticon lamp, mounted in a ventilating shaft. The former was far more efficient in inducing stimu- 
lation than the latter, since it not only produced a more intense light, but also a light which contained a greater percentage of rays of shorter wave length. Consequently, the results obtained in a given intensity of light produced by one lamp differ from those obtained in the same intensity of light produced by the other. The voltage of the current fluctuated somewhat, but it was usually about 115. A beam of light, admitted through a rectangular aperture $15 \mathrm{~mm}$. square, was reflected to the stage of the microscope by means of the substage mirror, set at an angle of $45^{\circ}$ (fig. 1). Different intensities were secured by moving the microscope closer to or farther from the light. A permanent scale in centimeters, made by careful measurement from the center of the lamp to the center of the stage, was constructed on the table supporting the microscope, making it possible to obtain rapidly and accurately any intensity desired. The light rays were usually passed through distilled water for absorption of heat, but in order that the microscope be as near the lamp as possible the distilled water was sometimes omitted, though only after careful experiment had shown that the heat was not sufficient to appreciably alter the reaction. Time was measured with a stop-watch or by counting the ticks from an Eastman timer. The latter method had the advantage of leaving both hands free for manipulation of apparatus, and was sufficiently accurate. The light was turned off either by means of an opaque screen or a camera shutter placed over the aperture in the shaft. With the shutter exposures could be made varying from $1 / 100$ to 1 second, but as it was not calibrated the time of the exposures made with it is to be considered only as approximate.

Intensity is indicated in the tables by considering the intensity at 100 centimeters from the light as 1 , and other distances on the same basis. Thus at $50 \mathrm{~cm}$. from the light the intensity amounted to 4 and at $25 \mathrm{~cm}$. it amounted to 16 . In the case of the 123-volt lamp 1 equals somewhat less than 1000 meter candles, and in the case of the 112-volt lamp somewhat more. Except in the experiments recorded in tables 6,8 , and 11 the 123 -volt lamp was used. 
Two species of Amoeba were used, A. proteus and A. discoides (Shaeffer, '20). Both species were cultivated in the laboratory in various culture solutions. A. discoides seemed to thrive best in a culture of wheat in spring water. A. proteus, which has been raised in the Zoölogical Laboratory of The Johns Hopkins University for a number of years, grew well in several solutions, including boiled hay in spring water, barley in distilled water, and oak leaves in spring water.

An amoeba usually responds to a sudden increase in the intensity of light by a cessation of flow that takes place rather suddenly, but it was found that animals which are sluggish sometimes slow up gradually. These latter were not well adapted for the experiments in hand, and as a consequence only vigorously flowing individuals were selected for experimentation. Apparently size and shape have no appreciable effect on the reaction. There appears also to be no greater variation between individuals of the two species than among individuals of the same species; consequently they were used indiscriminately.

In making the observations an amoeba was isolated in a drop of water that was free from debris, and placed on a slide within a ring of vaseline, which supported the cover-glass and prevented evaporation. The animal was then left in darkness in the dark room from fifteen to thirty minutes to insure thorough dark adaptation and to permit acclimatization to the temperature of the room. It was next placed under the microscope and illuminated by weak light from a small substage lamp, after which attention was focused on the streaming in the advancing pseudopod. The strong light from the stereopticon lamp was then flashed on suddenly by removing the screen, and the time which elapsed before the animal stopped was recorded. The stereopticon lamp was now turned off, and left off for three or four minutes, after which the observation was repeated. The number of observations made in succession on an individual varied from three or four to eighty, depending on the experiment and the condi- 

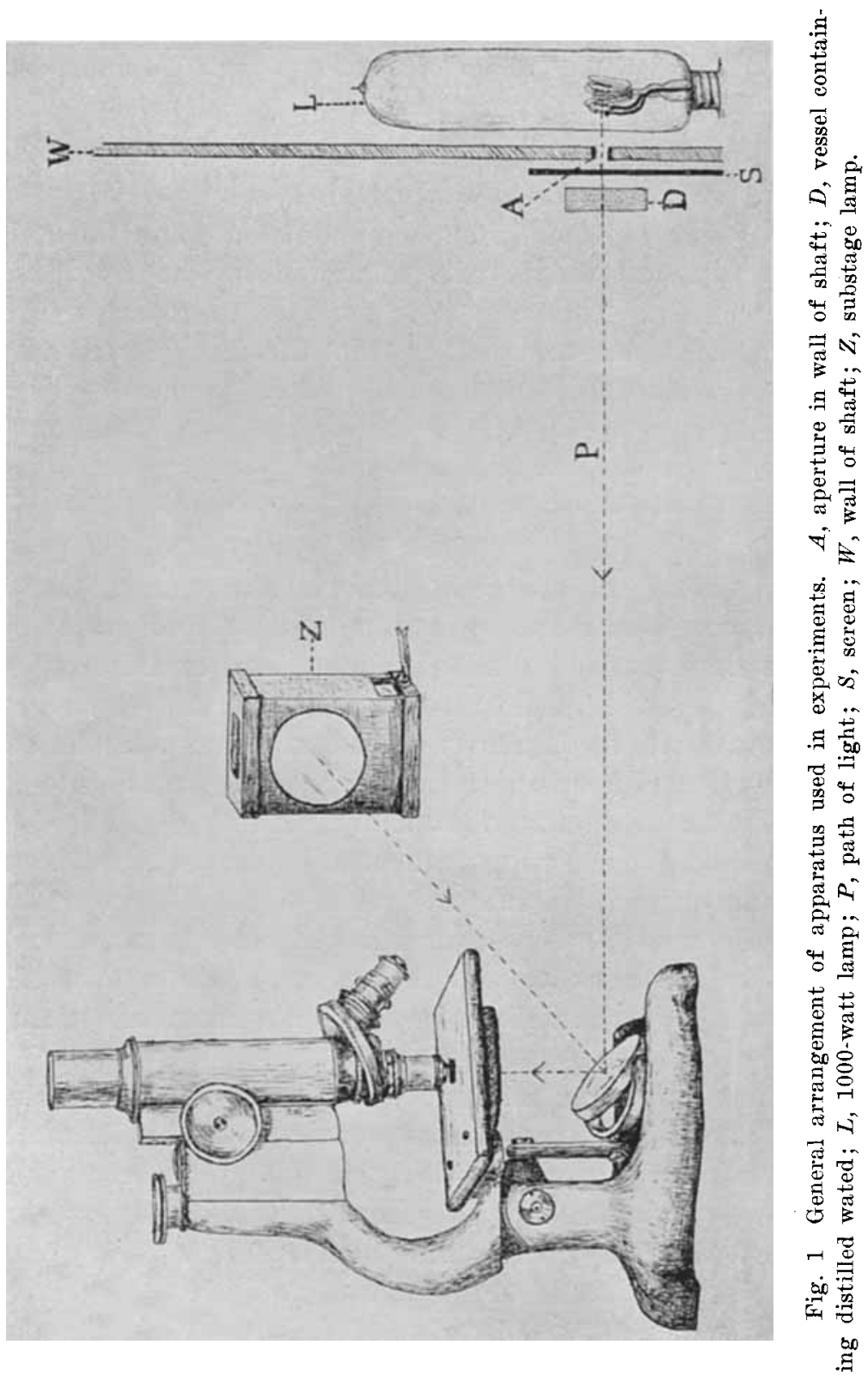
tion of the animal. Some amoebae ceased to react consistently after a few exposures, while others continued to react for hours. Unless otherwise indicated, only one individual was used for each experiment or set of experiments.

Variations in the above procedure were necessary for some experiments. These are described in the text.

Under favorable conditions the cessation following an increase in illumination is precise and sharp so that it can be clearly seen. This makes it possible to measure fairly accurately the time occupied by the different phases of the response. Amoeba is consequently very favorable for the work in hand.

THE REACTION-TIME, THE STIMULATION-PERIOD, AND THE LATENT PERIOD

It has already been stated that when an amoeba is subjected to a sudden increase in illumination it responds by a cessation of movement that takes place not immediately, but some time after the stimulation. This period which intervenes between the application of the stimulus and the reaction, known as the reaction-time, has been investigated, as previously stated, in a number of organisms.

In Amoeba the reaction-time usually varies little in successive exposures if the intensity of the light is kept constant. Thus, from table 1 , we see that in ten trials with a minute interval in the dark between them the mean reaction-time amounts to 2.5 seconds with a variation from the mean of only 0.25 second, or 10 per cent.

This does not mean that the variation is always so small. In the first place, if a specimen continues to be illuminated time after time with a relatively short period in darkness between reactions, the reaction-time finally becomes erratic; it may be considerably longer than at first, often several times as long, or there may be no response. This is probably due to fatigue. It can be avoided by leaving the animal in darkness for some time or by increasing the time between exposures. Secondly, there are frequently great variations 
in the reaction-time, quite apart from fatigue, and so far as discovered entirely independent of external conditions, as indicated in the results recorded in table 2. This table shows that the reaction-time fluctuated markedly until the ninth exposure, when it decreased suddenly and remained fairly constant. Such changes were noted in a number of instances. Sometimes, however, the reaction-time changed gradually, not suddenly as in the above example. These changes may consist of either an increase or a decrease in reaction-times. The causes underlying these variations are unknown.

TABLE 1

Showing the reaction-time in a given specimen subjected to successive exposures. One-minute interval in darkness between tests. Note that there is very little variation

\begin{tabular}{c|c|c|c}
\hline OBSERYATION No. & REACTION-TIME & OBSERVATION No. & REACTION-TIME \\
\hline & seconds & & seconds \\
1 & 2.75 & 6 & 2.25 \\
2 & 2.25 & 7 & 2.50 \\
3 & 2.25 & 8 & 2.25 \\
4 & 2.25 & 9 & 2.50 \\
5 & 2.25 & 10 & 2.25 \\
\hline
\end{tabular}

In the remainder of this paper, unless otherwise indicated, we shall consider only cases in which sufficient time was allowed between tests to avoid fatigue and in which the variation in reaction-time at any one intensity is little if any greater than in the experiment recorded in table 1.

As stated in the introduction, it has been found that the reaction-time in a number of different organisms is composed of two parts: the stimulation-period, a time during which exposure to light is necessary, and the latent period, a time during which exposure to light is not necessary in order to obtain a response.

The stimulation-period may be ascertained at any given intensity by decreasing in successive tests the length of the 
period during which the amoeba is in illumination until it no longer responds. The shortest period of exposure at which a response is obtained is the stimulation-period for that intensity. The results obtained by such a series of tests are presented in table 3. This table indicates that there were no reactions to exposures of 0.75 second, that there were two reactions in eight exposures of 1 second, that there were two reactions in four exposures of 1.25 seconds, and that there was a reaction for each exposure of 1.50 seconds or over. That exposure in which responses are obtained in half of the tests, in this case 1.25 seconds, is the shortest in which the chances of obtaining a response and no response are equal. We shall consider this as the stimulation-period.

TABLE 2

Showing sudden change in the reaction-time of a given individual. One-minute interval in darkness between tests

\begin{tabular}{|c|c|c|c|}
\hline OBSERVATION No. & REACTION-TIME & OBSHRVATION NO. & REACTION-TIME \\
\hline & seconds & & seconds \\
\hline 1 & 6.00 & 8 & No reaction \\
\hline 2 & 6.25 & 9 & 4.00 \\
\hline 3 & 5.50 & 10 & 3.00 \\
\hline 4 & 15.00 & 11 & 4.00 \\
\hline 5 & 7.50 & 12 & 3.75 \\
\hline 6 & No reaction & 13 & 3.25 \\
\hline 7 & 6.00 & 14 & 3.50 \\
\hline
\end{tabular}

The latent period, as stated above, is that part of the reaction-time during which it is not necessary that the organism be exposed to light in order to obtain a response. Consequently, it is the difference between the reaction-time and the stimulation-period. In the experiment, recorded in table 3 , the stimulation-period, as we have just seen, was 1.25 seconds and the total average reaction-time 4.66 seconds. The latent period was consequently 3.41 seconds. During this time the animal could be either in darkness or in light, without any effect on the reaction-time. In this way the stimulation-period was ascertained for a number of individuals. The results obtained are presented in table 4 . 
From this table it is at once apparent that the stimulationperiods and the latent periods vary in different individuals. The table shows that in an intensity of 16 the stimulationperiod varied from 0.90 second to 1.80 seconds and the latent period from 1.20 seconds to 2.60 seconds, and that in an intensity of 6.25 the former varied from 1.40 seconds to 2.10 seconds and the latter from 1.40 seconds to 3 seconds.

Just as the reaction-time sometimes fluctuates considerably at a constant intensity, so the stimulation-period and the latent period also occasionally show marked variations in successive tests, even though the intensity of the light remains

TABLE $\delta$

Illustrating method of obtaining stimulation- and latent periods. Reaction-time $=4.66$ seconds; stimulation-period $=1.25$ seconds; latent period $=3.41$ seconds

\begin{tabular}{|c|c|c|c|}
\hline LENGTH OF EXPOSURE & NUMBER OF TRIALS & NUMBER OF REACTIONS & AVERAGE REACTION-TIME \\
\hline seconds & & & seconds \\
\hline .75 & 2 & 0 & \\
\hline 1.00 & 8 & 2 & 4.63 \\
\hline 1.25 & 4 & 2 & 4.50 \\
\hline 1.50 & 6 & 6 & 4.75 \\
\hline 4.75 & 4 & 4 & 4.75 \\
\hline
\end{tabular}

unchanged. But just as in the case of the reaction-time, this is not usually true and need not concern us here.

While the reaction-time in constant illumination usually remains nearly constant, it varies greatly if the illumination is changed. The effect of changes in the luminous intensity is shown in table 5. Here it may be seen that at an intensity of 16 the reaction-time was 3.50 seconds, but that at an intensity of 4 it had increased to 5.50 seconds, at an intensity of 1 to 8.25 seconds, and at an intensity of 0.444 to 13.75 seconds. Increase in reaction-time with decrease in intensity was invariably met with in all of the numerous observations made. 
The results obtained in nearly all of these observations were plotted, with the ordinates as the reaction-time and the abscissae as the luminous intensity. All of the graphs thus obtained simulate an hyperbola. A fairly typical one is reproduced in figure 2. The dots in this graph represent the results of successive tests with 2-minute intervals.

Hecht and Obreshkove obtained similar results in observations on Ciona, Mya, and tadpoles. They maintain that the latent period is constant, and that their results, consequently,

TABLE 4

Showing individual variation in the latent period and stimulation-period. In this and the succeeding tables the intensity of the light produced by the 1000-watt lamp at a distance of $100 \mathrm{~cm}$. is indicated at 1. The other intensities are expressed as multiples of this; 16, e.g., indicating light 16 times as intense as that produced by a 1000-watt lamp at a distance $100 \mathrm{~cm}$.

\begin{tabular}{c|c|c|c|c}
\hline $\begin{array}{c}\text { INDIVIUCAL } \\
\text { No. }\end{array}$ & $\begin{array}{c}\text { RELATIV INTENSITY } \\
\text { OF LIGHT }\end{array}$ & REACTION-TIME & $\begin{array}{c}\text { LATENT } \\
\text { PERIOD }\end{array}$ & $\begin{array}{c}\text { STIMULATION- } \\
\text { PERIOD }\end{array}$ \\
\hline & & seconds & seconds & seconds \\
\hline 1 & 16 & 3.20 & 2.10 & 1.10 \\
2 & 16 & 3.00 & 1.20 & 1.80 \\
3 & 16 & 3.00 & 1.90 & 1.10 \\
4 & 16 & 3.50 & 2.60 & .90 \\
5 & 16 & 3.30 & 1.85 & 1.45 \\
6 & 6.25 & 3.90 & 2.50 & 1.40 \\
7 & 6.25 & 3.50 & 1.40 & 2.10 \\
8 & 6.25 & 5.00 & 3.00 & 2.00 \\
\hline
\end{tabular}

show that the amount of light-energy received during the stimulating period remains constant regardless of changes in luminous intensity. It is evident, as Hecht points out, that if the latent period and the energy received during the reaction-time remain constant during changes of intensity, the graph of the reaction-time will be an hyperbola, which is in accord with our results. But do these factors actually remain constant?

Since the stimulation-period varies inversely as the intensity, it follows that if the intensity is made great enough the stimulation-period should become so small as to be 
negligible, making the latent period and the reaction-time practically the same. By means of the Abbé condenser on the microscope, which greatly increased the intensity of the light, and a camera shutter which permitted short exposures, it was easy to prove that the stimulation-period was indeed very short under such conditions. Reactions were obtained occasionally by exposure of only $1 / 50$ of a second, and often with an exposure of $1 / 25$ of a second, though in nearly all cases the reaction-time amounted to one second or more. Thus in certain instances, the latent period and reaction-time were almost identical, and for all practical purposes could be

TABLE 5

Showing increase in reaction-time with decrease in luminous intensity

\begin{tabular}{c|c|c|c}
\hline LUMINOLS INT ENSITY & REACTION-TIME & LUMINoUs INTENSITY & HEACTION-TIME \\
\hline & seconds & & seconds \\
\hline 18.11 & 3.00 & 1.23 & 7.50 \\
16.00 & 3.50 & 1.00 & 8.25 \\
11.11 & 3.50 & .826 & 8.50 \\
6.25 & 5.00 & .694 & 9.50 \\
4.00 & 5.50 & .529 & 10.75 \\
2.78 & 6.33 & .510 & 12.25 \\
2.04 & 6.75 & .444 & 13.75 \\
1.56 & 7.25 & & \\
\hline
\end{tabular}

considered so. Numerous observations were made under these conditions and it was invariably found that the reactiontime obtained in very high intensity was considerably smaller than the latent period obtained in low intensities, indicating that the latent period is not constant. The evidence presented below supports this contention. It demonstrates, moreover, that the latent period does not remain constant over even a small range of intensities.

Since the stimulation-period (s) plus the latent period (l) equals the reaction-time $(\mathrm{r}), \mathrm{s}+\mathrm{l}=\mathrm{r}, \mathrm{s}=\mathrm{r}-\mathrm{l}$, $\mathrm{si}=(\mathrm{r}-\mathrm{l})$ $i$ and $s^{\prime} i^{\prime}=\left(r^{\prime}-l^{\prime}\right) i^{\prime}$ where $i$ and $i^{\prime}$ represent any two different intensities. The product of the luminous intensity and the time during which the light acts in the stimulation-period 
(si) equals the amount of light-energy received during this period. If this and the latent period (l) are constant, regardless of the magnitude of the intensity, then $s i=\mathrm{s}^{\prime} \mathrm{i}^{\prime}, \mathrm{l}=\mathrm{l}^{\prime}$, $(r-l) i=\left(r^{\prime}-1\right) i^{\prime}$ and $s i=\left(r^{\prime}-l\right) i^{\prime}$, when $r$ and $r^{\prime}$ are the reaction-times at intensities $i$ and $i^{\prime}$, respectively. If this

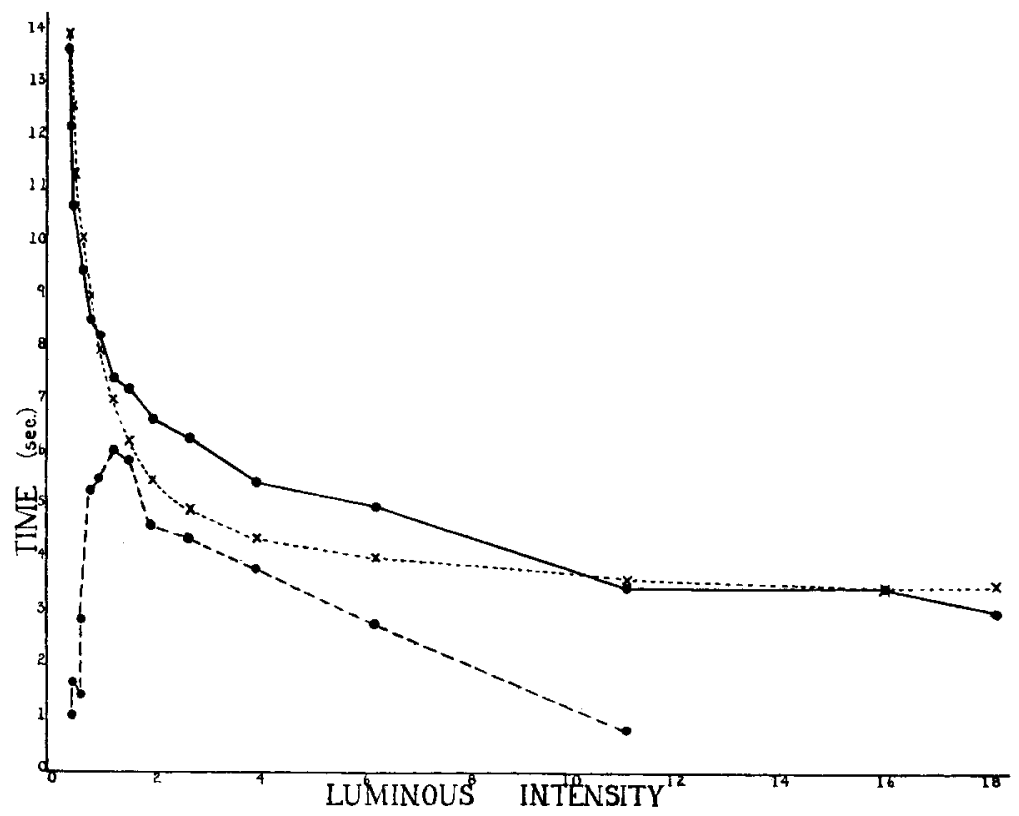

Fig. 2 Curves showing the reaction-time and the latent period at various intensities. Solid curve, reaction-time; broken curve, latent period; dotted curve, an hyperbola; circular areas on curves, points experimentally established. Note that while the reaction-time decreases with increase of intensity forming a curve which closely approaches an hyperbola, the latent period is not constant, showing clearly that the amount of light-energy necessary for stimulation varies with the intensity.

is true, it is evident that the reaction-time for any intensity can readily be ascertained by calculation if the latent period and the stimulation-period are known at one intensity, for $\mathrm{r}^{\prime}-\mathrm{l}=\frac{\mathrm{si}}{\mathrm{i}^{\prime}}$; and the latent period can be ascertained if the reaction-time at two intensities is known, for $r-1=\frac{\left(\mathbf{r}^{\prime}-1\right) i^{\prime}}{i}$.

Table 6 gives the results of observations made on ten specimens in which the latent period was ascertained both by ex- 
perimentation in the manner previously described and by calculation according to the formula $\mathrm{r}-\mathrm{l}=\frac{\left(\mathrm{r}^{\prime}-1\right) \mathrm{i}^{\prime}}{\mathrm{i}} . \quad B y$ referring to this table it will be seen that the total average latent periods obtained by experimentation and by calculation equal 1.65 and 1.77 seconds, respectively, a difference of only 0.1 second, which is well within the limits of experimental error. This indicates that the method of calculation is valid for averages of the results obtained in a number of tests. If the latent periods for a given individual are calculated for

TABLE 6

Comparison of latent period as obtained experimentally and by calculation from the reaction-times at three intensities as described in text

\begin{tabular}{|c|c|c|c|c|c|c|}
\hline \multirow{2}{*}{$\begin{array}{c}\text { DESTGNATION } \\
\text { OF INDVIDUAL }\end{array}$} & \multicolumn{4}{|c|}{ REACTION-TIMES AT INTENSITIES } & \multirow{2}{*}{$\begin{array}{l}\text { LATENT PERIOD } \\
\text { EXPERIMENTAL }\end{array}$} & \multirow{2}{*}{$\begin{array}{l}\text { LATENT PERROD } \\
\text { CALCTLATED }\end{array}$} \\
\hline & 16 & 11.1 & 6.25 & 4.0 & & \\
\hline 1 & 2.54 & 3.25 & 3.53 & & 2.03 & 1.91 \\
\hline 2 & 2.60 & 3.10 & 4.10 & & 2.10 & 1.95 \\
\hline 3 & & 3.25 & 3.80 & $4.40 \mid$ & 2.40 & 2.45 \\
\hline 4 & & 2.60 & 3.00 & $4.80^{l}$ & 1.20 & 1.05 \\
\hline 5 & 2.75 & 3.60 & 5.56 & & 1.40 & .95 \\
\hline 6 & 2.90 & 3.20 & 3.77 & & 2.20 & 2.34 \\
\hline 7 & 1.90 & 2.70 & 3.20 & & 1.70 & 1.05 \\
\hline 8 & & 2.70 & 3.20 & 4.72 & 1.20 & 1.36 \\
\hline 9 & & 3.00 & 3.88 & 4.33 & 2.25 & 2.47 \\
\hline 10 & 2.40 & 3.53 & 4.84 & & 1.05 & .92 \\
\hline \multicolumn{6}{|c|}{ Average .......................... 1.77} & 1.65 \\
\hline
\end{tabular}

two sets of intensities, there is a great difference in the two results obtained, but the mean of these two results agrees very well with the latent period obtained experimentally. For example, in individual (1) the latent period obtained by calculation from intensities 16 and 11.1 equals 0.93 second, that obtained from intensities 11.1 and 6.25 equals 2.89 seconds, while the mean equals 1.91 seconds, which agrees very well with the latent period 2.03 seconds experimentally obtained. The table shows that there was a similar agreement between calculated and experimental latent periods in reference to all of the other individuals represented. 
We therefore have a simple method of ascertaining approximately the latent period for one intensity if the reaction-time for three intensities is known. In table 7 are presented the results obtained by this method from data given in table 5. The stimulation periods ( $\mathrm{s}$ ) were obtained by subtracting the latent periods from the reaction-times and the energy (si) received during these periods by multiplying

TABLE 7

Showing change in latent period with change in intensity. Note that the latent period increases as the intensity decreases until a maximum is reached, beyond which it decreases; that the product of the stimulation-period and the intensity, on the other hand, decreases to a minimum, beyond which it increases; and that the maximum latent period and minimum product occur at the same intensity

\begin{tabular}{|c|c|c|c|c|}
\hline $\begin{array}{l}\text { RFIATIVE LUMINOLS } \\
\text { INTENSITY (i) }\end{array}$ & REACTION-TIME & $\begin{array}{l}\text { LATENT } \\
\text { PERIOD }\end{array}$ & $\begin{array}{l}\text { STIMULATION-PERTOD } \\
(\mathrm{s})\end{array}$ & $\begin{array}{l}\text { STIMLLATION-PERIOD } \\
\text { TIMES INTENSITY (SI) }\end{array}$ \\
\hline & seconds & seconds & seconds & \\
\hline 16.00 & 3.50 & & & \\
\hline 11.11 & 3.50 & .79 & 2.71 & 30.08 \\
\hline 6.25 & 5.00 & 2.84 & 2.16 & 13.50 \\
\hline 4.00 & 5.50 & 3.86 & 1.64 & 5.56 \\
\hline 2.78 & 6.33 & 4.39 & 1.94 & 5.39 \\
\hline 2.04 & 6.75 & 4.63 & 2.12 & 4.32 \\
\hline 1.56 & 7.25 & 5.96 & 1.29 & 2.01 \\
\hline 1.23 & 7.50 & 6.03 & 1.47 & 1.81 \\
\hline 1.00 & 8.25 & 5.56 & 2.69 & 2.69 \\
\hline .826 & 8.50 & 5.33 & 3.17 & 2.62 \\
\hline .694 & 9.50 & 2.87 & 6.63 & 4.50 \\
\hline .529 & 10.75 & 1.55 & 9.20 & 5.45 \\
\hline .510 & 12.75 & 1.62 & 10.63 & 5.42 \\
\hline .444 & 13.75 & 1.04 & 12.71 & 5.64 \\
\hline
\end{tabular}

them by the luminous intensities. In this table it is shown that at an intensity of 11.1 the latent period equals 0.79 second, that it increases as the luminous intensity decreases until at an intensity of 1.23 it equals 6.03 seconds, and that beyond this it decreases as the luminous intensity decreases, until at an intensity of 0.444 it equals only 1.04 seconds. From this table it can also be seen that the light-energy (si) received during the stimulation-period is greatest in the highest 
intensity, amounting to 30.08 at an intensity of 11.1, and that it decreases to 1.81 at an intensity of 1.23 , beyond which it increases to 5.64 seconds at an intensity of 0.444 . Thus it appears that as the latent period-increases the amount of light-energy acting during the stimulation-period decreases, and vice versa. This becomes strikingly evident in an examination of the curves presented in figures 2 and 3.

These results are entirely at variance with the conclusions of Blaauw, Arisz, Ewald, Hecht, and Obreshkove, who state emphatically that the amount of light-energy required to induce a reaction is constant, regardless of intensity.

From the results obtained in the experiments just described, we are justified in drawing the following conclusions: 1) the amount of light-energy required to induce a reaction is not constant in all intensities, but varies as the intensity varies; 2) the latent period is not constant, but likewise varies with the luminous intensity; 3 ) there is a certain correlation between the latent periods and the stimulationperiods, for as one increases with change of intensity the other decreases.

THE STIMULATION-THRESHOLD AND THE INTENSITY-THRESHOLD

We have seen that at any given intensity a definite amount of light-energy is required in order that a reaction may occur. If the period of exposure is too short or if the light is too weak, no response follows. The smallest amount of lightenergy that will call forth a response has been designated the stimulation-threshold, and the lowest intensity that will induce a response the intensity-threshold.

There has been some confusion in regard to the term stimulation-threshold. Blaauw ('09, '14) uses it to designate the quantity of light-energy necessary to cause plant seedlings to show a macroscopically visible bending toward the source of light. Arisz ('11), on the other hand, maintains that this is not a true threshold. He contends that long before this there has been a perceptible response to the light, indicated by a slight asymmetry at the tip of the plant, visible 
under magnification. He is of the opinion that it is impossible to definitely ascertain the first indication of a response.

A stimulus acting for too short a time to cause an amoeba to stop moving still has an effect, as indicated by a temporary retardation in the rate of flow, which takes place at about the time the animal would have stopped had the illumination been continued. As the period of exposure is decreased the retardation becomes less and less noticeable, until finally it is imperceptible; increase, on the other hand, causes a more and more marked retardation until it results in the characteristic cessation of flow. If one means by stimulation-threshold the smallest amount of light-energy that will call forth a response, irrespective of what that response is, it is impossible to define the term precisely, since one cannot say at just what period of exposure there ceases to be a retardation in the rate of flow. On the other hand, if the stimulationthreshold is defined as the smallest amount of light-energy that will produce a cessation of movement, it can be accurately ascertained.

In very high intensities the reaction-time becomes shorter as the period during which the animal is exposed to light is increased. Thus in a very high intensity an exposure of $1 / 25$ of a second yielded a reaction-time of 2.13 seconds, an exposure of $1 / 10$ of a second, a reaction-time of $1 / 5$ second, and an exposure of $1 / 4$ of a second, a reaction-time of $1 / 25$ second. It was, however, repeatedly observed that a limit is soon reached, and that any additional increase in the time during which the animal is illuminated has absolutely no effect on the reaction-time.

The decrease in the reaction-time, when the period of exposure is made longer, though invariably found when the luminous intensity is very high, is seldom if ever found in lower intensities; indeed, the results presented in table 3 seem to show that if there is any relation between length of exposure and reaction-time the shortest period of illumination that will induce a cessation of movement results in the shortest reaction-time that can be obtained. 
The lowest intensity at which a response can be obtained, as stated above, is called the intensity-threshold. It varies greatly among different amoebae. The intensity-threshold for the individual whose reaction-times are recorded in table 5 was in the neighborhood of 375 meter candles, but in most cases there ceases to be a response long before such a low intensity has been reached.

As the intensity of the light becomes too weak to induce a cessation of movement, the behavior is very similar to that in the case of understimulation in the higher intensities. At first there is a decided retardation in the rate of locomotion, which becomes less marked as the intensity decreases, finally becoming imperceptible.

From these results it may clearly be seen that, while it is true that one cannot definitely detect the smallest amount of light-energy or the lowest intensity that will induce a response, it is very easy to ascertain the smallest amount of light-energy or the lowest intensity that will produce a cessation of protoplasmic flow.

\section{DARK ADAPTATION}

If an amoeba, which has been in the dark, is suddenly exposed to light, and a reaction obtained, it must be subjected to darkness, or at least to a lower intensity, before a second reaction can occur. Certain processes take place within the organism when in the lower intensity, which lead back to the same physiological state that the animal was in before the exposure. These processes are known as dark adaptation. An organism is said to be dark adapted when it will respond to a sudden increase in the intensity of illumination. The converse of dark adaptation is light adaptation. This is brought about by exposure to light. An animal is said to be light adapted when from a lack of dark adaptation it fails to respond to a sudden increase in illumination.

An insufficient amount of time in the dark, following a reaction, results either in a failure to respond when an amoeba is exposed to light, or in a longer reaction-time. 
This is well illustrated in table 8. Amoeba no. 1, represented in this table, was subjected to a series of tests, in all of which it was kept in darkness for several minutes to insure perfect dark adaptation and then suddenly exposed to light and left until a response was obtained plus 60 seconds. The light was then turned off and left off for periods varying from 2.5 to 60 seconds in successive tests, after which it was again

TABLE 8

Showing dark adaptation. In a series of tests each amoeba was subjected to darkness for several minutes, and suddenly illuminated calling forth a reaction. The light was then left on for the periods indicated in the table, and turned off for periods which are also indicated, after which the amoeba was again illuminated, causing a second reaction and resulting in the reaction-times recorded in the table

\begin{tabular}{|c|c|c|c|c|}
\hline & & & & $\begin{array}{c}\text { AVERAGE } \\
\text { RGACTION-TIME }\end{array}$ \\
\hline Amoeba no. 1 & $\begin{array}{l}60 \text { sec. in light followed by } \\
60 \text { see. in light followed by } \\
60 \text { sec. in light followed by } \\
60 \text { sec. in light followed by } \\
60 \text { sec. in light followed by }\end{array}$ & $\begin{array}{r}2.5 \\
3 \\
5 \\
8 \\
15\end{array}$ & $\begin{array}{l}\text { sec. in dark } \\
\text { sec. in dark } \\
\text { sec. in dark } \\
\text { see. in dark } \\
\text { see. in dark }\end{array}$ & $\begin{array}{l}4.50 \text { sec. } \\
3.75 \text { sec. } \\
3.38 \text { sec. } \\
2.38 \text { sec. } \\
2.13 \text { sec. }\end{array}$ \\
\hline Amoeba no. 2 & $\begin{array}{l}90 \text { see. in light followed by } \\
90 \text { sec. in light followed by } \\
90 \text { sec. in light followed by } \\
3 \text { sec. in light followed by }\end{array}$ & $\begin{array}{r}5 \\
10 \\
15 \\
120\end{array}$ & $\begin{array}{l}\text { sec. in dark } \\
\text { sec. in dark } \\
\text { sec. in dark } \\
\text { sec. in dark }\end{array}$ & $\begin{array}{l}3.83 \text { sec. } \\
3.25 \text { sec. } \\
2.17 \text { sec. } \\
2.28 \text { sec. }\end{array}$ \\
\hline Amoeba no. 3 & $\begin{array}{l}60 \text { see. in light followed by } \\
60 \text { see. in light followed by } \\
60 \text { sec. in light followed by } \\
60 \text { sec. in light followed by }\end{array}$ & $\begin{array}{r}5 \\
10 \\
15 \\
20\end{array}$ & $\begin{array}{l}\text { see. in dark } \\
\text { see. in dark } \\
\text { sec. in dark } \\
\text { sec. in dark }\end{array}$ & $\begin{array}{l}4.67 \text { sec. } \\
3.25 \text { sec. } \\
2.70 \text { sec. } \\
2.60 \text { see. }\end{array}$ \\
\hline
\end{tabular}

flashed on and left until the animal reacted. As may be seen, the reaction-time for the second exposure amounted to 4.5 seconds, after the shortest period in the dark, and 2.13 seconds after the longest period. This decrease in reaction-time, however, soon reaches a minimum, after which a longer exposure to darkness has no effect in reducing it. Thus, in the case of amoeba no. 2, table 8, 90 seconds in the light followed by 15 seconds in the dark gave practically the same 
results as 3 seconds in the light followed by 120 seconds in the dark, showing that 15 seconds in darkness suffices for complete dark adaptation.

From this it might be concluded that complete dark adaptation takes place in 15 or 20 seconds, the time required in darkness in order to secure the lowest possible reaction-time. One might also infer that all the processes leading to complete

TABLE 9

Showing amount of time that must elapse after one reaction before a second reaction can occur. Except as indicated the procedure was the same as in the experiments recorded in table 8 . Note that during part of this time the individual may be in light

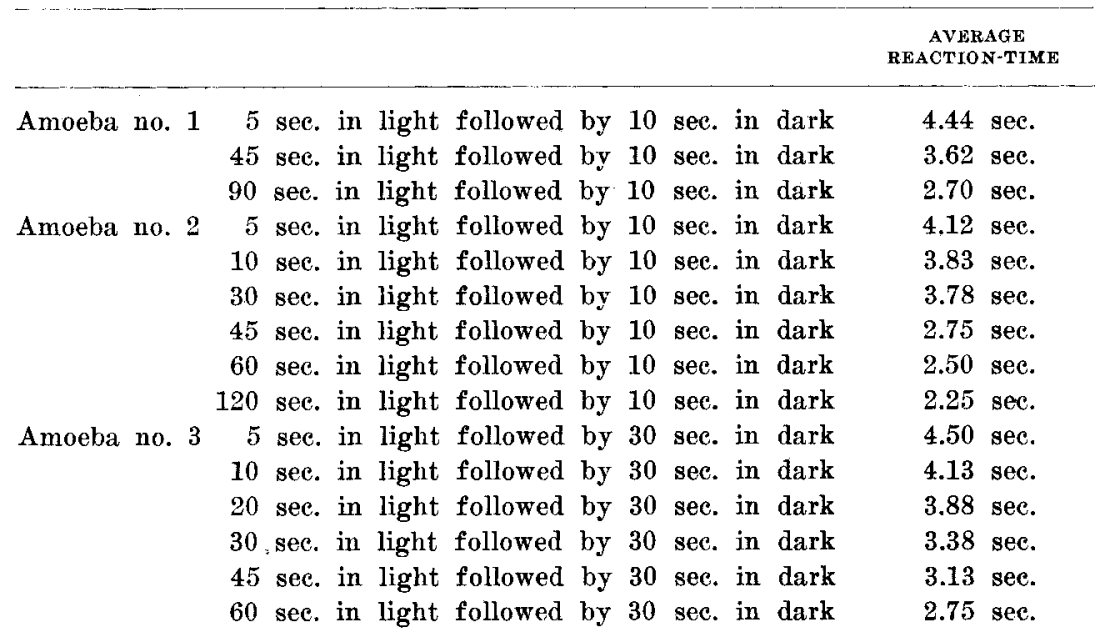

recovery from the shock produced by sudden illumination take place only in darkness. Such, however, is far from being the case.

If, in a series of tests similar to that described above, the time in darkness preceding the second reaction is kept constant, and the time in light following the first reaction is varied, it becomes evident that recovery is taking place not only while the animal is in the dark, but also before that time, while it is yet in the light. Thus, in the experiment recorded in table 9 , when after the first reaction amoeba 
no. 1 was kept in the light for 5 seconds, then placed in darkness for 10 seconds, and again suddenly exposed to illumination, the resulting reaction-time for the second reaction amounted to 4.44 seconds. When, however, instead of 5 seconds in the light following the first reaction, the animal was left 45 seconds, followed as before by 10 seconds in the dark, the reaction-time for the second reaction was 3.62 seconds, and when left 90 seconds in the light followed by 10 seconds in the dark it was only 2.70 seconds. This indicates clearly that partial recovery from the shock produced by sudden illumination may take place while the animal is in the light. The experiments with amoebae nos. 2 and 3 strongly support this conclusion.

This demonstrates conclusively that in Amoeba the recovery from shock resulting from sudden increase in light intensity is not a simple physiological process. It would perhaps be more accurate to assume that there are two sets of processes. One set of processes can occur only in the dark, or at least when the intensity of the light is lowered, and it is to this that the term dark adaptation should apply. The time required for this varies in different amoebae, but it is usually in the neighborhood of 15 to 20 seconds. The processes which take place immediately after the shock are entirely independent of darkness. They probably occur with equal rapidity in light or darkness. As a rule, they take much longer than the other and usually occupy from 1 to 2 minutes.

INFLUENCE OF THE ENVIRONMENT OF THE REACTION-TIME

\section{a. Individual variations}

In investigating the reactions to light in Amoeba one is immediately struck by the fact that there are marked individual variations. It is indeed seldom that two individuals are encountered whose reaction-times are the same at any given intensity, or which require the same amount of time for dark adaptation, or in which the intensity or stimulation- 
thresholds are identical. Figure 3 presents a typical example of extreme variation in reaction-time. From this figure it is seen that at an intensity of 16 the reaction-times of various individuals ranged from 2 seconds to more than $6 \frac{1}{2}$ seconds, with an equally great range at several other intensities.

Notwithstanding these individual differences, experimentation soon shows that the reactions of specimens from the same culture are much more likely to be similar than those from diverse cultures.

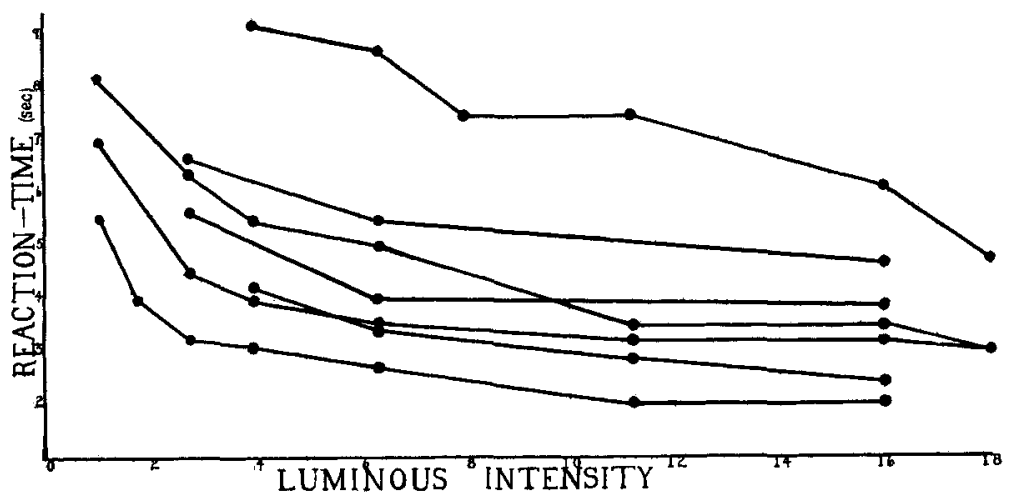

Fig. 3 Showing individual variation. Curves constructed as the curve in figure 2 .

\section{b. Relation between mechanical shock and the reaction to light}

A very interesting relationship is brought out if an amoeba is subjected to a mechanical shock and immediately afterward exposed to a sudden increase in illumination. The effect of a mechanical shock on locomotion depends upon its magnitude. If it is very weak, the animal responds either by a temporary quickening, followed by retardation, in the rate of locomotion, or by a momentary cessation of protoplasmic flow which takes place after a short latent period. If the shock is made stronger, the amoeba remains stationary for a longer period of time. A comparatively heavy shock results in an almost instantaneous cessation of motion, the advancing 
pseudopod is retracted violently, and the animal tends to assume a spherical form. In resuming locomotion a number of small pseudopods are protruded and the flow is very erratic, taking place first in one of these small pseudopods, then in another until normal locomotion finally results. Upon the condition in which the mechanical shock leaves the animal depends its reaction when exposed to light.

In testing the effect of mechanical shock on reactions to light, the cover-glass was jarred with a pencil, and this was followed at various intervals with a sudden increase in illumination. Obviously, it was impossible to control the magnitude very definitely. The jarring was usually just sufficient to bring about a retardation or a short cessation of flow, but in one case it was strong enough to cause a retraction of the pseudopods-a condition indicated in table 10 by means of an asterisk. From this table it is seen that when the shock is not too strong the animal ordinarily either does not respond to the sudden increase in illumination which follows or the reaction-time is considerably longer than when the illumination is not preceded by a shock; and that when the light is turned on after a strong shock, that is during the time when the erratic flow described above is in progress, a reactiontime is obtained that is no longer than usual. In fact, it is often much shorter.

\section{c. Influence of feeding on the reaction-time}

One soon finds that the reaction-time of an amoeba that is feeding varies greatly in successive exposures.

Amoeba lives upon smaller organisms which are engulfed and retained within the body until digested. The victim is captured by means of pseudopods which flow around it, the ends fusing and forming a cup, the top of which is still open and the bottom bounded by the substratum. The cup is soon closed, however, by sheets of protoplasm. After the prey has been engulfed, especially if it is large, the amoeba becomes sluggish, small pseudopods are protruded and an erratic flow is to be observed like that which takes place in the recovery from a strong mechanical shock. 
When the food cup is being formed and the pseudopods are flowing around the prey, there is no response to light, no matter how great the increase in intensity may be. More than fifty observations were made on amoebae forming food cups, and in no case was a reaction obtained, although in all instances responses to the same increase in illumination

\section{TABILE 10}

Showing the effect of mechanical shock on the reaction time. In those observations marked 'disturbed' the cover-glass was jarred slightly with a pencil, followed shortly by exposure to light. In all others there was no mechanical shock. All were exposed to the same intensity of light. *, indicates strong mechanical shock.

\begin{tabular}{|c|c|c|}
\hline OBSERVATION NO. & CONDITION OF AMOEBA & REACTION-TIME \\
\hline & & seconds \\
\hline 1 & & 2.50 \\
\hline 2 & & 2.25 \\
\hline 3 & Disturbed & No reaction \\
\hline 4 & & 2.50 \\
\hline 5 & Disturbed & No reaction \\
\hline 6 & & 3.00 \\
\hline 7 & & 2.50 \\
\hline 8 & & 2.75 \\
\hline 9 & Disturbed & 7.00 \\
\hline 10 & & 2.25 \\
\hline 11 & & 2.50 \\
\hline 12 & Disturbed & $2.50^{*}$ \\
\hline 13 & & 2.50 \\
\hline 14 & & 1.50 \\
\hline 15 & Disturbed & 7.00 \\
\hline 16 & & 2.00 \\
\hline
\end{tabular}

occurred when no food cups were forming. Table 11 illustrates this very clearly in a single individual. This table shows further that after the animal has fed, while the erratic flow that has just been described is taking place, the reactiontime is shorter than under normal conditions. It has been found in the experiments that not only is the reaction-time shorter under such conditions, but that the amount of lightenergy necessary to cause a response is also smaller. 


\section{d. Effect of temperature on the reaction-time}

It is difficult to control precisely the temperature of unicellular organisms when under observation. However, by means of a Pfeifer warming stage a large range of temperature, from $10^{\circ} \mathrm{C}$. to $27^{\circ} \mathrm{C}$. was secured. Little or no effect was noted in the reaction-time. No attempt was made to study the influence of temperature on dark adaptation.

TABLE 11

Showing the effect of feeding on the reaction-time. Note that when the animal is feeding it fails to respond to light, and that after the food has been taken in the reaction-time becomes shorter than usual. Three or four minutes between exposures

\begin{tabular}{|c|c|c|}
\hline OBSERVATION NO. & CONDITION OF AMOEBA & REACTION-TMME \\
\hline & & seconds \\
\hline 1 & & 5.00 \\
\hline 2 & Just fed & 3.20 \\
\hline 3 & & 3.00 \\
\hline 4 & & 4.20 \\
\hline 5 & & 5.20 \\
\hline 6 & Feeding & No reaction \\
\hline 7 & & 3.20 \\
\hline 8 & Just fed & 2.60 \\
\hline 9 & & 5.00 \\
\hline 10 & Feeding & No reaction \\
\hline 11 & & 2.60 \\
\hline 12 & & 3.20 \\
\hline 13 & Just fed & 2.20 \\
\hline 14 & & 1.60 \\
\hline 15 & & 3.20 \\
\hline 16 & & 3.60 \\
\hline 17 & Feeding & No reaction \\
\hline 18 & & 3.60 \\
\hline 19 & & 5.60 \\
\hline 20 & & 6.20 \\
\hline 21 & & 6.00 \\
\hline 22 & Just fed & 3.60 \\
\hline
\end{tabular}




\section{DISCUSSION}

Blaauw, Fröschel, Arisz, and others have assumed a photochemical reaction in accounting for the response to light in plants. Mast ('07) postulated a reversible photochemical reaction to explain reversion in the sense of photic orientation in Volvox, and Hecht makes use of the same idea in attempting to explain the reactions of Ciona and Mya to a sudden increase in illumination. Hecht assumes the presence of a reversible photosensitive substance, designated $\mathbf{S}$, which under the influence of light is changed into its precursors, designated $\mathrm{P}$ and $\mathrm{A}$, and which is reformed in darkness. $\mathrm{He}$ assumes that the quantity of the precursors formed under the influence of the light must bear a definite ratio to the amount present before the light was turned on in order to obtain a reaction; that the stimulation-period is the time necessary to convert this required amount of $S$ into its precursors, and that the latent period is a time during which other reactions occur, which need not be considered here.

The reactions to light in Amoeba are not in accord with this view. As a matter of fact, there is considerable evidence which seems to indicate that the response to light by Amoeba is not the result of a photochemical reaction at all. We have seen that, although one or two minutes must elapse after a reaction before another can occur, most of this time may be spent in light. Certainly, during the time that may be spent in the light no process of a reversible photochemical nature can be at work. We have also seen that there is a close relationship in Amoeba between the effects produced by mechanical shock and sudden increase in illumination. A mechanical shock, as previously noted, produces a cessation in streaming just as light does, and after a reaction to a mechanical shock, just as after a photic shock, a period must be allowed for the animal to recover before a reaction to light can be obtained. This seems to indicate that the processes involved in response to mechanical stimulation and to photic stimulation are fundamentally the same, that mechanical shock produces the same sort of changes in the 
organism as sudden increase in illumination. Only in this way can the effect of the one on the other be explained, and these processes cannot be photochemical in nature.

A reaction similar to that following sudden increase in illumination has been obtained by sudden increases in other forms of stimuli. Ewart ('03) states that streaming protoplasm in cells of Chara and Nitella responds to a mechanical shock by a cessation of movement, and, as with light, the shock to be effective must be applied suddenly. He says (p. 73) :

The more suddenly the force is applied, the more powerful is its reaction, a smart shock being much more effective than one applied gradually. Thus if bodies of different weight are allowed to fall on the cover-slip from such heights that they have the same momentum on impact, the smaller body with the higher velocity exercises the greater shock effect. . . . . A shock which is not sufficiently powerful to cause a complete stoppage may produce a more or less marked retardation, usually of short duration.

This, it must be admitted, is very similar to the effect produced by light in Amoeba. Ewart also states that a sudden lowering in temperature causes a cessation of movement in streaming protoplasm in cells in Chara and Nitella.

What, then, is the nature of the response to photic stimulation in Amoeba? That, we must admit, the results obtained do not show. We have seen that although the intensity of the light remains constant the response differs in different individuals and even in the same individual at different times. We have seen that equal quantities of light do not necessarily produce equal effects. We have seen that after one response a certain period of time must elapse before a second reaction can occur, and that more than one process takes place during this time. And we have seen that the response to light is closely related to certain other processes, such as feeding and mechanical shock. From all these data one is inclined to think that the reaction must result from a series of changes, probably a very complex series of changes, in the organism. Of what this series consists further experimentation alone will show. 
SUMMARY

1. Amoeba responds to a sudden increase in illumination by complete cessation of movement.

2. This cessation does not take place immediately after the light is increased. The time which intervenes is known as the reaction-time.

3 . There are marked individual variations in the reactiontime, but the variations are not so great in amoebae of the same culture as in those of diverse cultures.

4. It is not necessary that the animal be exposed to light for the entire reaction-time in order to obtain a response. The time during which illumination is required is known as the stimulation-period and the remaining part as the latent period. The latent period may be spent either in darkness or in light.

5. At any given intensity the reaction-time, the latent period, and the stimulation-period usually remain practically constant, although changes may occur.

6 . The reaction-time varies inversely with the luminous intensity.

7. The latent period is dependent upon the intensity of the light, being comparatively short in a very strong light, but increasing in length as the intensity of the light decreases, until a maximum is reached beyond which it decreases.

8. The amount of light-energy received during the stimulation-period decreases as the illumination decreases, until a minimum is reached, beyond which it increases. The minimum is found in the same intensity as the maximum latent period.

9. As a consequence of this correlation, the curve that results when the sum of the stimulation-period and latent period, the reaction-time, is plotted against the luminous intensity may simulate an hyperbola.

10. The latent period and the stimulation-period may be found either directly by experiment, or indirectly by calculation from reaction-times which are obtained experimentally.

11. In order to obtain a response after an amoeba has once responded to a sudden increase in illumination, a certain length of time, usually from one to two minutes, must elapse. 
12. The first part of this period may be spent either in darkness or in light, the succeeding reaction-time being the same in either case. The latter part, usually from ten to twenty seconds, must be spent in darkness, or at least in a lower intensity. The processes acting during this time are known as dark adaptation.

13. Incomplete dark adaptation is manifested by an increase in the reaction-time or by failure to respond.

14. There are two sets of processes which must take place after a reaction before another can occur. One set takes place only in the dark or low intensity, the other in either light or darkness.

15. A mechanical shock exerts a distinct effect upon the reaction to light. If the shock is slight, an increase in illumination immediately following it results in a longer reaction-time than usual or no reaction. If the shock is so heavy as to cause a retraction in the pseudopods, an increase in illumination just as the animal is recovering results in an exceptionally short reaction-time.

16. This indicates that increase in illumination and mechanical shock produce the same changes in Amoeba, that mechanical stimulation and photic stimulation are fundamentally the same. If this is true, it is evident, since mechanical stimulation is not photochemical, that photic stimulation cannot be photochemical.

17. An amoeba which is forming a food cup invariably fails to respond to a sudden increase in illumination. After the food cup is formed, however, the stimulation-period and the reaction-time are often shorter than usual.

18. Temperature apparently exerts little if any effect upon the reaction-time. 


\section{LITERATURE CITED}

Arisz, W. A. 1911 On the connection between stimulus and effect in photo* tropic curvatures of seedlings of Avena sativa. Proc. Kon. Akad. Wet. Amsterdam, pp. 1022-1031.

1915 Untersuchung über den Phototropismus. Rec. trav. bot. Néerlandais, Bd. 12, S. 44-216.

Baranetski, J. 1876 Influence de la lumière sur les plasmodia des Myxomycetes. Mem. Soc. Sc. nat. Cherbourg, T. 19, pp. 321-360.

Blaauw, A. H. 1909 Die Perzeption des Lichtes. Rec. trav. bot. Néerlandais, Bd. 5, S. 209-377.

1914 Licht und Wachstum. Zeitschr. f. Bot., Bd. 6, S. 641-703.

DAvenport, C. B. 1897 Experimental morphology, vol. 1, New York.

EngelmanN, T. W. 1879 Über Reizung contraktilen Protoplasmas durch plötzliche Beleuchtung. Arch. f. d. ges. Physiol., Bd. 19, S. 1-7.

EwaLd, W. F. 1914 Versuche zur Analyse der Licht- und Farbenreactionen eines Wirbellosen (Daphnia pulex). Zeitschr. f. Sinnesphysiol., Bd. 48, S. $285-324$.

Ewart, A. J. 1903 On the physies and chemistry of protoplasmic streaming in plants. Oxford Press, London.

Fröschel, P. 1909 Untersuchung über die heliotropische Präsentationszeit. Sitzb. k. Akad. Wiss., Wien, math.-nat. Cl., Bd. 118, Abt. 1, S. 1247-1294.

HARDER, R. 1920 Über die Reaktionen freibeweglicher pflanzlicher Organismen auf plötzliche Änderungen der Lichtintensität. Zeitschr. f. Bot., Bd. 12, S. $352-462$.

Harrington, N. R., and Leaming, F. 1900 The reactions of Amoeba to light of different colors. Amer. Jour. Physiol., vol. 3, pp. 9-16.

Hechт, S. 1918 The photic sensitivity of Ciona intestinalis. Jour. Gen. Physiol., vol. 1, pp. 147-166.

1919 Sensory equilibrium and dark adaptation in Mya arenaria. Jour. Gen. Physiol., vol. 1, pp. 544-588.

Mast, S. O. 1907 Light reactions in lower organisms. II. Volvox. Jour. Comp. Neur. and Psych., vol. 17, pp. 99-180.

1910 Reactions in Amoeba to light. Jour. Exp. Zoöl., vol. 9, pp. 265-278.

1911 Light and the behavior of organisms. New York.

1912 Behavior of fireflies (Photinus pyralis?) with special reference to the problem of orientation. Jour. Animal Behavior, vol. 2, pp. 256-272.

Obreshkove, V. 1921 The photic reactions of tadpoles in relation to the Bunsen-Roscoe law. Jour. Exp. Zoöl., vol. 34, pp. 235-279.

Shaffrer, A. 1920 Amoeboid movement. Princeton.

Stahl, E. 1884 Zur Biologie der Myxomyceten. Bot. Ztg., Bd. 40, S. 146-155; $162-175 ; 187-191$.

Verworn, M. Psycho-physiologisebe Protistenstudien. Jena: Fischer. 